\title{
The Fact of Quality Management in Health Clubs in El-Sharqiya Governorate
}

\section{Gehan Yahia Mahmoud ${ }^{1}$}

\author{
${ }^{1}$ Assistant Professor at the Health Sciences Department, Faculty of Physical Education for Girls, Zagazig University, Egypt
}

\begin{abstract}
The natural approach towards happiness and welfare for the human is one of the results of health and wellness, as it is difficult to enjoy life without them. Illness of course causes trouble in life, and this fact is confirmed by saying that health is a crown on the heads which one cannot know its value, until he/she suffers from pain and disease Salama (2007).

The availability of health services in the community is of the most important factors that affect the health of individuals; these services are presented in hospitals and health units and centers, as well as the necessary hardware and equipment.

Sport is a social phenomenon that has recreational, physical, health and mental targets, such as having fun, entertaining, removing tension and self-expression. It reflects the values and core needs of the individual, especially in the modern era, so it becomes a good idea to do some exercise in spare time under supervision of specialized companies in the field, such as health clubs which has spread largely recently with the society's recognition of the importance of devoting some time to relax and take a break and get away from daily pressures and burdens. The demand for such destinies is increasing day after day because of health awareness among the attendants of the clubs and the importance of exercise under the supervision of specialists in order to fully benefit and scientifically of it. (17), Ibrahim (2005).
\end{abstract}

\section{Introduction:}

$\mathrm{T}$ The natural approach towards happiness and welfare for the human is one of the results of health and wellness, as it is difficult to enjoy life without them. Illness of course causes trouble in life, and this fact is confirmed by saying that health is a crown on the heads which one cannot know its value, until he/she suffers from pain and disease Salama (2007).

The availability of health services in the community is of the most important factors that affect the health of individuals; these services are presented in hospitals and health units and centers, as well as the necessary hardware and equipment.

Sport is a social phenomenon that has recreational, physical, health and mental targets, such as having fun, entertaining, removing tension and self-expression. It reflects the values and core needs of the individual, especially in the modern era, so it becomes a good idea to do some exercise in spare time under supervision of specialized companies in the field, such as health clubs which has spread largely recently with the society's recognition of the importance of devoting some time to relax and take a break and get away from daily pressures and burdens. The demand for such destinies is increasing day after day because of health awareness among the attendants of the clubs and the importance of exercise under the supervision of specialists in order to fully benefit and scientifically of it. (17), Ibrahim (2005).

A health club is a place where anyone can improve his/her health and efficiency of the body organs. Health is considered one of the most important things in life; which ranks first for individual's priorities in life Qassem \& Abdel-Fattah (2004).

Walter Skok and Andrew Kophamel pointed to the increasing popularity of health clubs industry and seeking for health, fitness and leisure, this led to an increased competition among many health clubs, which offers services to their customers and their visitors, therefor they decided to set information systems as a means of identifying the needs of their visitors, to provide the best services and highest quality and gain a competitive advantage Walter, Andrew \& Ian (2001)

The fast growing scientific and technical development accelerated led to an increase in the number of projects and competition has increased between them which prompted organizations to look for methods and management techniques that enable them to raise the level 
of those organizations and improve the quality of their services in order to attract customer interest and increasing demand for the use of these services Aly (2002).

The concept of quality management is relatively considered of the modern concepts that began to be used in some organizations that seek to improve the quality of services provided to customers in order to gain their satisfaction. This helps the employees to perform their duties in a perfect way of awareness, participation, efficiency, creative thinking and problem solving Hilal (2000).

Applying quality management in the organization requires creating an atmosphere in order to understand, convict and accept the employees regarding the concepts and practices of quality management because it would contribute in cooperation and commitment and reduce their resistance to change, the organization also can operate convincing the employees by explaining the new system by holding seminars and lectures in the field of quality and providing education and training programs Federal Quality Institute (1990)

Some researchers believe that one of the necessary requirements for quality is a system based on precise measurement of appropriate statistical methods to identify shortcomings and weaknesses in performance and implementation of processes and activities, and working on developing a plan for corrective actions to improve the services provided so as to provide them a competitive advantage in the field health services. The primary purpose of a system of standards is to identify prerequisites in the services provided, that are in line with customers' needs and that take into account the quality of service and reducing submitted costs as well.

Providing and establishing information system for quality management will contribute significantly to focus on the customer to provide all relevant information for him/her, starting with identifying him/her needs, desires and aspirations, and finishing with reporting the extent of satisfaction and saturation. This enables the health clubs to improve their competitive position and achieve excellence over competitors, and reinforce the link between them and the continuous attendants Qassem \& Abdel-Fattah (2004), Zein-Eldin (1997).

\section{Problem of the study:}

Due to the increasing popularity of health clubs in ElSharqiya governorate, along with the increase in the number of health clubs in its counties and villages, which offers the services of sports, health and entertainment to their attendants, which vary from person to another according to their age and state of health, each individual either man or woman has his/her requirements. We would find those who want to lose weight, increase or maintain it, as we find those who want to exercise to maintain health, or to improve fitness, or rehabilitate of nervous or mental effort, or to spend leisure time in work, or those who maintain the state of health after what or illness rehabilitation after injury. This agrees with what was said by "Mehanna" (2013). Popularity of health clubs also spread among university students who had intentions for submitting to the military colleges, this led to the administrations of those health clubs to pay more attention for the quality of services provided by them, whether they it is sport, entertainment or health services, as the quality is an important strategy in the marketing process to increase the quality of services and reduce costs, thus increasing the profits of these institutions.

In spite of having in mind the importance of the method of using quality management in the various organizations, however, the typical and traditional management style that ignores the interest of human tenets within the organization and paying attention to proper climate for work still exists. It was clear of the previous studies and the researcher's work in the field of quality for more than ten years that the use of quality management disproportionately affects the activity of the organizations, some studies have also shown that some of the institutions lacked the overall quality recipes as noted by "Abbas" (2013). Here comes the interest of the researcher to study the effect of quality management in health clubs as a method of an administrative direction to ensure the quality of service provided because this will provide guidance and proposals based on scientific bases and contribute to the increasing demand of individuals to those clubs which necessarily mean improvement in the level of health of individuals and society.

\section{Research goals:}

The research aims to identify:

1- The effect of quality in health clubs in El-Sharqiya governorate from the perspectives of the clubs' clients.

2- The effect of quality in health clubs in El-Sharqiya governorate from the perspectives of the clubs' employees.

\section{Research questions:}

1- What is the effect of quality in health clubs in ElSharqiya governorate from the perspectives of the clubs' clients? 
2- What is the effect of quality in health clubs in ElSharqiya governorate from the perspectives of the clubs' employees?

\section{Research procedures:}

\section{Research methodology:}

The researcher used the descriptive approach using the survey method with appropriate steps to the nature of the research.

\section{Research community:}

The research community consisted of all clients of the health clubs, (employees - administrators - supervisors trainers) in health clubs in Zagazig.

\section{Research sample:}

It was randomly selected and consisted of:

1- (292) clients

2- (56) administrators, supervisors and trainers.

Data collection tools:

\section{Questionnaire:}

1- A questionnaire to the health clubs' clients included (4) axes.

2- A questionnaire to the health clubs' employees included (3) axes.

This is because health clubs rely on customers for its sustainability and success, so it is necessary to understand the current and future needs as well as meeting these needs and try to exceed their expectations.

One of the club's important responsibilities is to afford appropriate environment that allows the employees to participate actively in achieving the goals, and to maintain this environment, so it was important to take into consideration the suggestions of the workers in the clubs and how satisfied they are with the quality management within the clubs to improve and develop the performance.

The researcher distributed the questionnaire to the sample units in the period from Sunday, 5/10/2014 to Monday, 20/10/2014.

\section{Statistical processors}

The researcher used SPSS software

\section{Presentation and discussion of the results:}

Table (1)

Responses of the clients according to the phrases of the axes of questionnaire to the health clubs' clients $(\mathrm{N}=292)$

\begin{tabular}{|c|l|c|c|}
\hline S & \multicolumn{1}{|c|}{ axes } & Mean & ${\text { Range of } \text { chi }^{2}}$ \\
\hline 1 & human resources of the club & 79.390 & $38.47-405.04$ \\
\hline 2 & physical facilities & 22.075 & $49.31-334.97$ \\
\hline 3 & Accessibility of the service & 17.222 & $136.98-178.02$ \\
\hline 4 & service units & 108.958 & $15.82-449.61$ \\
\hline
\end{tabular}

$\mathrm{Chi}^{2}$ value at $(0.05)=5.99$

Table (1) shows that the arithmetic means of the responses of the health club clients regarding the axis of (human resources of the club) ranged from $(2.544,2.931)$, and the arithmetic mean of the total of the axis was (79.390), which indicates a high level to the axis of human resources of the club.

There were also statistically significant differences in favor for the responses with "yes" in all axis phrases, which is based on the performance of quality of the health club in terms of preparation, training and development regarding the efficiency of dealing with the club's clients.

The researcher believes that the quality of health clubs, aims to identify the needs of the clients regarding the offered service or the desired characteristics in the health club, where the quality development within the health club effectively helps keeping on the clients of the health club, resulting in healthy habits to follow health systems and practicing sports activities and also follow diets help to establish healthy behaviors among the trainees which will benefit them healthy in all respects.

This agrees with Rady (2002) where he confirmed the need for the availability of a complete information system in addition to the availability of participation of employees in the improvement processes, which leads to a higher quality of services provided by the club.

Yehya (2012), Ibrahim (2009) and Sayed (2006) too have confirmed these findings previously in their studies.

Mahmoud Naguib's (2003) study indicates that most of the goals of fitness centers are achieved by implementing the programs and providing the physical and human resources within the centers. 
Table (1) shows that the arithmetic means of the responses of the health club clients regarding the axis of (physical facilities) ranged from $(2.626,2.893)$, and the arithmetic mean of the total of the axis was (22.075), which indicates a high level to the axis of physical facilities.

There were also statistically significant differences in favor for the responses with "yes" in all axis phrases, which refer to physical facilities. All of these facilities help the clients keep on practicing at the health club, and it is consistent with what is noted by Bayoumi (2011)

Table (1) shows that the arithmetic means of the responses of the health club clients regarding the axis of (Accessibility of the service) ranged from (2.842, 2.890), and the arithmetic mean of the total of the axis was (17.222), which indicates a high level to the axis of accessibility of the service.

There were also statistically significant differences in favor for the responses with "yes" in all axis phrases. All of these facilities help the clients keep on practicing at the health club, especially when they feel bored to do exercise by themselves.

Rotem, Gur, and Arie (1992) point that the existence of consensus between the needs of the client and the services of the health club, where the services and facilities are available, leads to customer satisfaction and thus the success of the club.

Table (1) show that the arithmetic means of the responses of the health club clients regarding the axes of (service units) ranged from $(2.188,2.934)$, and the arithmetic mean of the total of the axis was (108.958), which indicates a high level to the axis of service units.
There were also statistically significant differences in favor for the responses with "yes" in all axis phrases, which refer to the availability of services and activities in the club and availability of different devices and appropriate spaces for performing various exercises in addition to providing good lighting, music, etc., as well as diversity training offered that meets the needs of many visitors to the club, also the availability of rooms for sauna and steam featuring devices and characterized by fine temperature and humidity, and fit with the different age groups, also the presence of the Jacuzzi, which helps relaxing and the ability to adjust the temperature of the water for the users and of course the cleanliness of the water and changing it periodically to maintain healthy atmosphere for the clients to increase the motivation to exercise, massage rooms are also available and equipped with massage beds designed for massage and it is easy to adjust its temperature, the presence of qualified specialists for all types of massage is an important factor too.

All of these facilities help the clients keep on practicing at the health club and benefits of it, as they work on improving the vital organs of the body and maintain physical fitness, is also helping to relax after a hard day of work which increases the individual's ability to bounce back to continue to work well.

Ishikawa Hidetoshi (2005) noted that it is important to identify the most important basics and programs that help the success of the management of the gymnasiums.

There is no doubt that practicing sport is a very important and useful habit to maintain health of the human being and to prevent diseases, and it also has a positive impact on the brain and the immune system Qassem \&Abdel-Fattah (2004) (14: 134).

Table (2)

Responses of the clients according to the phrases of the axes of questionnaire to the health clubs' employees $(\mathrm{N}=56)$

\begin{tabular}{|l|l|c|c|}
\hline S & \multicolumn{1}{|c|}{ axes } & Mean & Range of chi $^{2}$ \\
\hline 1 & club management support & 20.678 & $7.0-30.14$ \\
\hline 2 & Competition requirements & 19.392 & $7.0-24.14$ \\
\hline 3 & Focusing on the client & 17.196 & $7.0-69.57$ \\
\hline
\end{tabular}

$\mathrm{Chi}^{2}$ value at $(0.05)=5.99$

Table (2) shows that the arithmetic means of the responses of the health club clients regarding the axis of (club management support) ranged from $(1.821,2.500)$, and the arithmetic mean of the total of the axis was (20.678), which indicates a high level to the axis of club management support.

There were also statistically significant differences in favor for the responses with "yes" in the phrases 4, 5, 6 and 7 which refer to club management support in which the management of the clubs are aware that they are responsible for setting a system supporting developing the quality and achieving the requested goals which commensurate with the clients' needs, so it is necessary to provide the appropriate environment where the employees would find themselves and this of course will improve the work performance level by giving the opportunity for the employees to submit queries. 
There were statistical significant differences in favor to the responses of "average" in the phrases (1, 2, 3, 8 and 9), so the management has to pay more attention for developing and improving the employees' performance and work on finding adequate opportunities to get them involved in workshops in order to support the development of technical skills and personal abilities, and work to recruit highly efficient human cadres, in order to assist management in pursuing continuous improvement of administrative processes and remove the obstacles and problems that may have faced.

Table (2) shows that the arithmetic means of the responses of the health club clients regarding the axis of (competition requirements) ranged from (2.107, 2.821), and the arithmetic mean of the total of the axis was (19.392), which indicates a high level to the axis of competition requirements.

There were also statistically significant differences in favor for the responses with "yes" in the phrases 1, 3, 4, 5, 6,7 and 8 , while there were statistically significant differences in favor for the responses with "average" in phrase 2.

This indicates that the health clubs in the El-Sharqiya governorate became aware of the importance of preserving what has been or expected to be achieved in new competitions, this is through the creation of flexible administrative means enables the clubs to coordinate and follow up the improvement process efforts, and evaluating the performance of employees continuously according to the clients' needs, the results also show that the health clubs in El-Sharqiya governorate is keen to develop information systems that operate and follow-up development of the services consistent with the cost and price of the service and the speed expected for clients, though still needs to be developed and modernized, the clubs also are keen on the physical aspects of choosing a good location for the club as well as the appearance of the employees (administrators, supervisors and trainers) in terms of (tact, respect, well appearance). This result is consistent with those indicated by the results of ElTarawnah \& El-Belbisy (2002), which concluded that the commercial banks in Jordan adopt the concept of focusing on the competitive managerial needs to strengthen their positions in the market.

Table (2) shows that the arithmetic means of the responses of the health club clients regarding the axis of (focusing on the client) ranged from $(1.750,2.821)$, and the arithmetic mean of the total of the axis was (17.196), which indicates a high level to the axis of focusing on the client.
There were also statistically significant differences in favor for the responses with "yes" in all axis phrases, which indicates that the health clubs in El-Sharqiya governorate see in the client an important strategic factor for its survival in the market, and therefore it is natural to set long-term and short-term plans in order to ease access for knowledge for the client and to create communication systems working to facilitate access about the client's data for the management officials and provide various programs and services to meet the desires and needs of their clients and to follow up their complaints and provide appropriate solutions, because the client is considered the capital of these clubs, without him/her there will not be benefit, this agrees with the study of Bastawy (2013).

\section{Conclusions and recommendations:}

\section{(I) Conclusions:}

1- Quality management is applied at high levels in health clubs in El-Sharqiya governorate from the perspectives of their clients.

2- Quality management is applied at high levels in health clubs in El-Sharqiya governorate from the perspectives of their employees.

3- There are statistically significant differences between the clients who have more than one year and the ones who have less than one year in the axis of (human resources of the club) in favor to those who have less than one year.

4- There are no statistically significant differences between males and females in the axes of the questionnaire of the fact of quality management within the health clubs.

\section{(II) Recommendations:}

1- Health clubs in El-Sharqiya governorate have to apply quality management according to the modern standards because of its importance for their sustainability.

2- Health clubs in El-Sharqiya governorate need to continue providing modern and advanced equipment as well as qualified and well-prepared human resources, in order to attract clients and keep them through achieve their needs.

3- Health clubs in El-Sharqiya governorate would pay attention to their experienced employees, through providing courses and lectures and organizing rehabilitation programs that contribute to the development and improvement of their skills in using modern equipment and tools. 
4- Further studies may be conducted regarding the quality management on various fields of sport management in order to know how to apply the concepts and methods of total quality in the sports fields of different types.

\section{References:}

1- Abbas Fahd Hamza (2013): "Evaluation of Health Clubs and the Effectiveness of Preventive and Rehabilitative Procedures for Injuries in the State of Kuwait", PhD thesis, Faculty of Physical Education for Boys, Alexandria University, Egypt.

2- Aly Mia (2000): "Total Quality Management and the Possibility for Applying It in the Institutions and Public Sector Companies for Aluminum Industry and the General Company for Manufacturing Electric Motors in Latakia", Vol. 22, No. 2.

3- Bastawy Heba Ahmed (2013): “Total Quality Management as an Introduction for Developing the Managerial Performance of Health Clubs in Alexandria", Master thesis, Faculty of Physical Education for Boys, Alexandria University, Egypt.

4- Bayoumi Doaa Mohamed (2011): "Management Policies of Hotel Services and Its Relationship with the Quality of Health Clubs", Master thesis, Faculty of Physical Education for Girls, Helwan University, Egypt.

5- El-Tarawnah Mohamed Ahmed and El-Belbisy Badriya Moataz (2002): "Total Quality and Organizational Performance: Case Study on Commercial Banks in Jordan”, Mu0'tah for Research and Studies, Vol. 7, No. 1, Jordan.

6- Federal quality institute,(1990). federal total quality management hand book, united state office of personnel management, Washington,p7.

7- Hilal Mohamed Abdel-Ghany (2000): "The Total Quality Management in Training", Cairo, Performance Improvement and Development Center.

8- Ibrahim Kamal Hassan (2009): "The Quality of Service Standards at Health Clubs and the Psychological Impact on the Attendants", PhD thesis, Faculty of Physical Education for Boys, Alexandria University, Egypt.

9(2005): "Evaluating the Health Clubs of Greater Cairo Hotels", Master thesis, Faculty of Physical Education for Boys, Benha branch of Zagazig University, Egypt.
10- Ishikawa Hidetoshi (2005): Sports Gym Management Method Program And Device.

11- Mahmoud Mahmoud Najeeb(2003): Evaluation of Recreational Programs in physical fitness centers in great Cairo, unpublished Master thesis, Faculty of Physical Education for Boys, Helwan University, Egypt.

12- Mehanna Mohamed Ibrahim (2013): "Trends of Health Club Attendants in Leisure Time," Master thesis, Faculty of Physical Education for Boys, Helwan University, Egypt.

13- Qassem. Medhat and Abdel-Fattah Ahmed (2004): "Health Clubs (Health and Fitness - Weight Loss - Body Building)",Cairo, Dar Al-Fikr Al-Araby.

14- Rady Bahgat Atiya (2002): “Total Quality Management as an Introduction for Developing the Management of Egyptian Sport Clubs in the Light of Contemporary Global Transformations", unpublished $\mathrm{PhD}$ thesis, Faculty of Physical Education for Boys, Helwan University, Egypt.

15- Rotem, Gur, Arie(1992): The Importance Of The Appropriate Segmentation Approach And Strategic Fit Between Users \& Clubs In The Health Club, Ph D. University Of Illinois At Urbana Champaign.

16- Salama Bahaa-Eldin (2007): "Health and Health Education",Cairo, Dar Al-Fikr Al-Araby.

17- Sayed Ramy Mohamed (2006): "Requirements of Total Quality Management of Health Clubs in the Governorates of Cairo and Giza", Master thesis, Faculty of Physical Education for Boys, Helwan University, Egypt.

18- Walter Skok, Andrew Kophamel Z\& Ian Richardson(2001): "Diagnosing information systems success: importance-performance maps in the health club industry", Kingston Business School, Kingston University, Kingston Hill, Kingston upon Thames, Surrey KT2 7LB, UK.

19- Yehya Shaimaa Mohamed (2012): “Active Management of the Human Factor and Its Role in the Quality of Performance and Satisfaction of Beneficiaries at the Health Clubs", PhD thesis, Faculty of Physical Education for Girls, Helwan University, Egypt.

20- Zein-Eldin Farid (1997): "Intellectual and Philosophical Framework for the Entrance of Total Quality Management", Journal of Management, Vol. 33, No. 1.

21- www.asharqalawsat.com 